\title{
The Effects of Total Lymphocyte Deficiency on the Extent of Atherosclerosis in Apolipoprotein E-/- Mice
}

\author{
Alan Daugherty, ${ }^{\star \ddagger}$ Ellen Puré, ${ }^{\S}$ Dustie Delfel-Butteiger, ${ }^{\star}$ Sam Chen, ${ }^{\S}$ John Leferovich,, Simon E. Roselaar, ${ }^{\star}$ \\ and Daniel J. Raderl| \\ *Cardiovascular Division, Department of Medicine, and ${ }^{\ddagger}$ Department of Biochemistry and Molecular Biophysics, Washington University

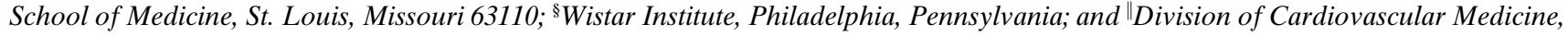 \\ Department of Medicine, University of Pennsylvania, Philadelphia, Pennsylvania 19104
}

\begin{abstract}
Activated T lymphocytes are present in human atherosclerotic lesions and autoantibodies to antigens within lesions have been detected in serum, but the roles of the cellular and humoral immune systems in atherogenesis have not been determined. The effect of total lymphocyte deficiency on atherogenesis was investigated by crossing apo E-deficient mice (which develop atherosclerosis resembling human disease) with mice deficient in RAG2 (which is required for normal B and T lymphocyte development). Mice were placed on a fat- and cholesterol-enriched diet for $\mathbf{1 2}$ wk. RAG2-deficient mice had no serum autoantibodies, in contrast to the high titers in RAG2 $+/$ - littermates. There were no $\mathrm{T}$ lymphocytes and a markedly reduced number of MHC class II-positive macrophages in atherosclerotic lesions of RAG2-deficient mice. Despite these differences, RAG2-deficient mice developed atherosclerosis similar in extent to that in immunocompetent littermates, based on quantification by two independent methods. In conclusion, the absence of autoantibodies and $\mathrm{T}$ lymphocytes did not influence the extent of aortic atherosclerotic lesions in apo E-deficient mice. (J. Clin. Invest. 1997. 100:1575-1580.) Key words: cell mediated immunity • humoral immunity
\end{abstract}

\section{Introduction}

Lymphocytes have been demonstrated to have an essential role in vascular lesions induced by transplantation (1). This cell type also modulates lesions produced by vascular injury $(2$, $3)$. Both the cellular and humoral immune systems have also been implicated in the pathogenesis of atherosclerosis (4) although their roles have not been clearly defined.

$\mathrm{T}$ lymphocytes are a prominent feature of atherosclerotic lesions in humans (5). This cell type is among the earliest recruited to lesions (6) and it accumulates in specific regions in advanced lesions $(7,8)$. T lymphocytes in human atherosclerotic lesions are polyclonal $(9,10)$ and the majority are acti-

Address correspondence to Alan Daugherty, Division of Cardiovascular Medicine, University of Kentucky, L543 KY Clinic, Lexington, KY 40536. Phone: 606-323-8040; FAX: 606-257-5804; E-mail: adaugherty@pop.uky.edu

Received for publication 15 March 1997 and accepted in revised form 22 July 1997.

J. Clin. Invest.

(C) The American Society for Clinical Investigation, Inc. 0021-9738/97/09/1575/06 \$2.00

Volume 100, Number 6, September 1997, 1575-1580

http://www.jci.org vated (11). It has been hypothesized that they influence atherogenesis through interactions with macrophages $(12,13)$ and smooth muscle cells (14). Despite these theoretical considerations, the role for $\mathrm{T}$ lymphocytes in the atherogenic process is unknown.

Humoral immunity has been postulated to play a critical role in atherogenesis through the generation of autoantibodies to antigens within lesions. Heat-shock protein 60 is one candidate antigen (15), although most attention has focused on autoantibodies to modified low density lipoprotein (LDL). Serum titers of antimalondialdehyde (MDA) ${ }^{1}$-LDL antibodies have been correlated with extent of atherosclerotic disease in humans (16). Autoantibodies directed against antigens such as MDA-LDL could influence atherogenesis through the interaction of immune complexes with macrophages within lesions $(17,18)$. However, the effects of ablation of autoantibodies on atherogenesis has not been defined.

To determine whether cellular and humoral immune mechanisms are passive bystanders or active participants in atherogenesis, the immune system has been manipulated by a variety of means. Pharmacologic studies using cyclosporin A have shown both increased $(19,20)$ and decreased $(21)$ atherosclerosis in animal models of the disease. Antibody immunodepletion (22) and genetic immune deficiency in mice (23) were used to address the role of $\mathrm{B}$ and $\mathrm{T}$ lymphocytes in atherogenesis. However, these studies used C57BL/6 mice fed a high cholesterol and cholate-containing diet. In this model, mice have small lesions limited to the aortic root that contain no $\mathrm{T}$ lymphocytes (24). Therefore, the interpretation of these studies with regard to the impact of the immune system on atherogenesis is uncertain. In contrast, T lymphocyte infiltration is an early and prominent feature of atherosclerotic lesions in apo E-deficient mice $(25,26)$. Furthermore, serum titers of autoantibodies to modified LDL are high (27). Because of these immunologic factors and the complex morphology of atherosclerotic lesions in these animals, which closely resembles that in humans $(28,29)$, the apo E-deficient mouse is currently considered a more appropriate model for investigation of mechanisms of atherogenesis $(30,31)$.

To investigate the hypothesis that lymphocytes influence the development of atherosclerosis in apo E-deficient mice, we introduced a deficiency in the recombinase activator gene 2 (RAG2) onto an apo E-/- genetic background. RAG2 deficiency results in a total deficiency of $\mathrm{B}$ and $\mathrm{T}$ lymphocytes (32). Mice with deficiencies of both apo E and RAG2 were bred to ensure an equivalent genetic background to control immunocompetent littermates. Atherosclerosis was quantified by two independent methods. Despite the absence of autoanti-

1. Abbreviations used in this paper: MDA, malondialdehyde; RAG, recombinase activator gene. 
bodies and $\mathrm{T}$ lymphocytes within atherosclerotic lesions, and the marked reduction in MHC class II-positive macrophages in lesions, RAG2 deficiency had no significant effect on the extent of aortic atherosclerotic lesion development.

\section{Methods}

Mouse breeding and diets. Apo E-/- mice were obtained from The Jackson Laboratory (Bar Harbor, ME). This strain was developed by Dr. Maeda on a $129 / \mathrm{J}$ background and had been backcrossed six times to C57BL/6J mice (33). RAG2-/- mice were obtained from GenPharm International (Mountain View, CA). These mice were also generated on a 129/J background. Apo E-/ - mice were bred to RAG2-/- mice to generate F1 offspring that were heterozygous for both genes. The F2 offspring of the F1 interbreeding were screened by measurement of serum cholesterol concentrations at 4 wk of age as an indication of apo E genotype. Mice identified as potentially apo $\mathrm{E}-/-$ based on serum cholesterol concentrations of greater than 300 $\mathrm{mg} / \mathrm{dl}$ were confirmed as apo E-/- by Southern blotting, as described previously (33). The RAG2 genotype was identified by PCR, as described previously (32). To control for differences in genetic background, apo $\mathrm{E}-1-\times \mathrm{RAG} 2-/-$ mice were bred to apo $\mathrm{E}-/-\times$ $\mathrm{RAG} 2+/-$ mice to generate litters that were all apo $\mathrm{E}-/-$ but either RAG2 $-/-$ or RAG2 $+/-$. Findings in RAG2 $-/-$ mice were compared with those in RAG2+/- littermates.

When they were 4 wk of age, mice were placed on a normal laboratory diet supplemented with $0.15 \% \mathrm{wt} / \mathrm{wt}$ cholesterol and $20 \% \mathrm{wt} /$ wt butter fat (Dyets, Bethlehem, PA), as described previously (28) and were maintained on this diet for 3 mo.

Phenotyping. Single-cell suspensions of splenocytes from each animal were analyzed by flow cytometry by use of FACScan and CellQuest software (Becton Dickinson, Franklin Lakes, NJ). FITCconjugated monoclonal antibodies against IgM (Bet2; 34) and CD3 $(2 \mathrm{C} 11 ; 35)$ were used to detect $\mathrm{B}$ and $\mathrm{T}$ lymphocytes, respectively. FACS $^{\circledR}$ analysis was corroborated by immunocytochemical analysis of frozen tissue sections of OCT-embedded spleens.

Lipids and lipoprotein characterization. Serum total cholesterol concentrations were determined with enzymatic assay kits (Sigma Chemical Co., St. Louis, MO) on a Cobas Fara autoanalyzer (Roche Diagnostic Systems Inc., Nutley, NJ). Lipoprotein cholesterol distributions were evaluated in pooled serum samples $(120 \mu \mathrm{l})$ from four mice in each group after fractionation by fast protein liquid chromatography (FPLC) gel filtration (Pharmacia LKB Biotechnology, Uppsala, Sweden) on two Superose 6 columns connected in series (36). Fractions were collected and cholesterol concentrations were determined with an enzymatic based assay kit (Wako Bioproducts, Richmond, VA).

Serum autoantibody titers to MDA-modified LDL. Human LDL ( $d=1.019-1.063 \mathrm{~g} / \mathrm{ml})$ was obtained under sterile conditions by sequential ultracentrifugation of human plasma. MDA was synthesized from 1,1,3,3-tetramethoxypropane, and MDA-LDL was produced as described by Haberland et al. (37). Autoantibodies titers were determined as described previously (20). Blood was allowed to clot and serum was separated by centrifugation and stored at $-20^{\circ} \mathrm{C}$. 96-well flat-bottom plates (Nunc Inc., Maxisorp F16, Fisher Scientific Co.), were washed with PBS and the wells were filled with $100 \mu$ l of either native LDL or MDA-LDL at a concentration of $10 \mu \mathrm{g} / \mathrm{ml}$. After incubation overnight at $4^{\circ} \mathrm{C}$, wells were washed three times with PBS and blocked with $3 \%$ BSA. After washing with PBS, duplicate wells were incubated at room temperature for $2 \mathrm{~h}$ with $100 \mu \mathrm{l}$ of serum at the indicated dilutions in $1 \%$ BSA. Wells were washed three times with PBS, and autoantibodies were detected by addition of biotinylated rat antimouse IgG (Vector Laboratories, Inc., Burlingame, CA) followed by horseradish peroxidase conjugated to avidin. Immunoreactivity was determined by addition of the chromogen 2,2'-azino-bis(3-ethylbenzthiazoline 6-sulfonic acid). Absorbance at $405 \mathrm{~nm}$ was determined with an automated plate reader. Titers of autoantibodies were expressed as absorbance of MDA-LDL binding minus that of LDL binding.

Immunocytochemical characterization of atherosclerotic lesions. Mice were perfused with PBS via a cannula placed in the left ventricle, with fluid drained from a severed right atria. The hearts from PBS-perfused mice were severed from the aorta at the base, embedded in OCT, and frozen in isopentane/liquid $\mathrm{N}_{2}$. Spleens were similarly embedded in OCT and frozen. Serial sections $(8 \mu \mathrm{m})$ were mounted on masked slides. Sections were fixed in acetone, air dried, and rehydrated in Dulbecco's modified PBS containing $0.02 \% \mathrm{NaN}_{3}$ and blocked first with $3 \% \mathrm{BSA}$ in $\mathrm{PBS} / \mathrm{NaN}_{3}$, followed by $3 \%$ normal goat serum in $\mathrm{PBS} / \mathrm{BSA} / \mathrm{NaN}_{3}$. Endogenous peroxidase was quenched with $3 \% \mathrm{H}_{2} \mathrm{O}_{2}$ in PBS. Sections were incubated with optimal concentrations of the indicated primary monoclonal as determined by optimal immunostaining of sections of spleen, followed by biotinylated goat anti-rat or anti-hamster secondary antibody (Vector Laboratories, Inc.) in the presence of $200 \mu \mathrm{g} / \mathrm{ml}$ normal mouse $\mathrm{IgG}$ to block reactivity with endogenous mouse immunoglobulin. Antibody reactivity was detected by use of the Vectastain Elite horseradish peroxidase-conjugated biotin-steptavidin complexes and developed with diaminobenzidine tetrahydrochloride as the chromogenic substrate. Immunostaining was photographed under brightfield on a Leitz microscope. Image analysis was performed to determine the density of cells expressing MHC class II as described previously (25).

Quantification of atherosclerotic lesions. Aortic tissue was removed from the ascending aorta to the ileal bifurcation and placed in freshly prepared $4 \%$ paraformaldehyde in PBS overnight at room temperature. After tissue fixation, adventitial tissue was carefully removed. The intimal surface was exposed by a longitudinal cut through the inner curvature of the aortic arch that extended down the whole length of the aortic tree. To permit the arch region to be laid out flat, the greater curvature was cut down to the level of the left subclavian artery. The tissue was laid out on a black background and an image of the aorta was recorded.

To quantify extent of intimal surface covered by grossly discernible lesions, image analysis was performed with Image-Pro (Media Cybernetics, Silver Springs, MD). Extent of atherosclerotic lesions was quantified in the arch, thorax, and abdominal regions. The regions were defined as follows: $(a)$ arch, from the ascending arch to 4-mm distal to the left subclavian artery; $(b)$ thorax, from the arch to the last intercostal artery branch; and $(c)$ from the thorax to the branch of the ileal bifurcation. The percent intimal area covered by lesions was quantified by two observers. There was routinely $<5 \%$ difference between the determinations of the two observers.

Unesterified and esterified cholesterol content of the aortic regions described above was determined by gas chromatography (38) as described previously $(39,40)$. Briefly, sterols were extracted from tissue as described by Bligh and Dyer (41) in the presence of $5 \alpha$-cholestane $(10 \mu \mathrm{g})$ as an internal standard. Total cholesterol was determined after saponification. Tissue content of sterols $\left(\mu \mathrm{g} / \mathrm{mm}^{2}\right)$ was normalized to the intimal surface area as determined by image analysis.

Statistical analysis. The null hypothesis for the variables measured in the two groups was initially tested by Student's $t$ tests. If the data did not fit the constraints of this parametric test, data were analyzed with the Wilcoxon rank-sum test. All statistical analyses were performed by use of SigmaStat (Jandel Scientific, San Rafael, CA). Data are presented as means \pm SEM.

\section{Results}

Serum cholesterol concentrations in apo E-/- $\times$ RAG2-/mice are not different from their immunocompetent littermates. Apo E-/ - mice develop hyperlipidemia and atherosclerosis even when fed a normal laboratory diet $(42,43)$. However, feeding a diet enriched in fat and cholesterol accelerates the development of the disease without affecting mor- 
phological characteristics of the disease (28). In this study the diet promoted a substantial hypercholesterolemic response that did not differ in RAG2 heterozygous and homozygous deficient animals: serum total cholesterol was $2,002 \pm 681$ versus $2,263 \pm 537 \mathrm{mg} / \mathrm{dl}$ for the heterozygous $(n=25 ; 13$ female and 12 male) and homozygous ( $n=14$; five female and nine male) mice, respectively. Furthermore, lipoprotein cholesterol distributions were not different in the two groups, as determined by size exclusion gel chromatography (data not shown).

Serum autoantibody titers to $M D A-L D L$ are high in immunocompetent apo $E-/-$ mice but absent in apo $E-/-\times$ $R A G 2-/-$ mice. Titers of autoantibodies to antigens within lesions such as heat shock protein 60 (15) and MDA-LDL (16) have been related to the extent of atherosclerotic disease in humans, but a cause-effect relationship has not been proven. It has been reported that apo E-/- mice develop high autoantibody titers to MDA-LDL (27). Under the conditions of this study, high serum titers of autoantibodies to MDA-LDL were present in apo $\mathrm{E}-/-\times \mathrm{RAG} 2+/-$ mice, but as expected, no MDA-LDL autoantibodies were detected in serum from apo E-/ $\times$ RAG2-/- mice (Fig. 1).

$T$ lymphocytes are absent and MHC class II-expressing macrophages are markedly reduced in atherosclerotic lesions of apo $E-/-\times R A G 2-/-$ mice. T lymphocytes were present in lesions of immunocompetent apo $\mathrm{E}-/-$ mice as reported in other mice strains with this genetic deficiency $(25,26)$. In contrast, as expected, atherosclerotic lesions from RAG2-/mice were devoid of T lymphocytes (data not shown). A considerable number of leukocytes within lesions expressed high levels of MHC class II in RAG2+/- mice (Fig. 2 C; 207 \pm 47 cells per $\mathrm{mm}^{2}$ ). Since B lymphocytes were not detected in le-

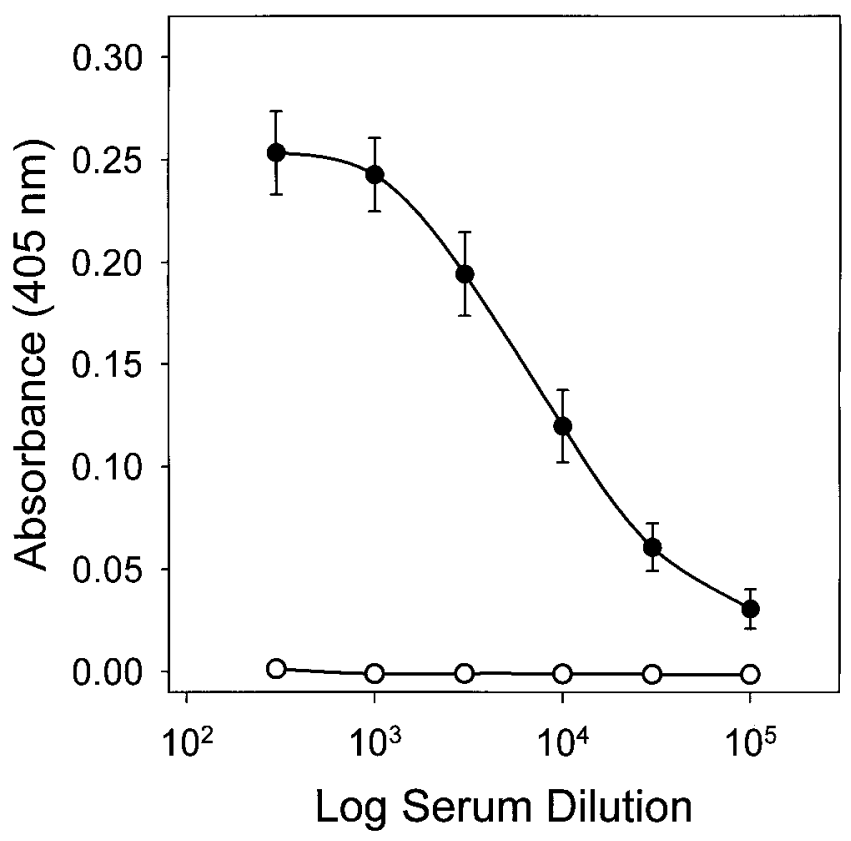

Figure 1. Serum titers of MDA-LDL autoantibodies. Serum titers of autoantibodies to MDA-LDL were determined in apo $\mathrm{E}-/-\times$ RAG2+1- (closed circles) and apo E-I- $\times$ RAG2-I- (open circles) mice by ELISA, as described in Methods. Symbols represent the means of serum from five randomly chosen animals in each group and bars represent SEM. sions and murine T lymphocytes do not express MHC class II, the MHC class II-expressing cells in CD45 positive regions of lesions were identified as macrophages. Activated T lymphocytes elaborate cytokines that increase MHC class II expression in macrophages. Therefore, upregulation of MHC class II expression may be one consequence of $\mathrm{T}$ lymphocytes that infiltrate lesions. Although some nonlipid engorged macrophage populations in lesions from $\mathrm{RAG} 2+/-$ mice had very strong MHC class II expression, foam cells in lesions of this strain only expressed low levels. These data suggest either that foam cells were derived from a subset of macrophages expressing little MHC class II or that formation of this cell type results in decreased density of MHC class II.

There were markedly fewer MHC class II-positive macrophages present in lesions of RAG2-/- mice ( $70 \pm 13$ cells per $\left.\mathrm{mm}^{2} ; P<0.005\right)$, although they were often associated with the endothelium (Fig. $2 \mathrm{D}$ ). This distinct reduction in $\mathrm{MHC}$ class II-positive macrophages within atherosclerotic lesions was evident despite equivalent expression of MHC class II on CD45 positive cells in adventitial tissue (Fig. 2) and spleens of RAG2-/- mice (data not shown). These data suggest that expression of MHC class II on infiltrating macrophages in lesions and/or recruitment of MHC class II-positive macrophages into lesions is lymphocyte dependent.

Lymphocyte-deficient apo E-/- mice develop atherosclerotic lesions similar in extent to those in immunocompetent littermates. The extent of atherosclerosis was determined in defined segments of the aorta from the ascending arch to the ileal bifurcation. The distribution of lesions in the mice we studied was similar to that described previously in apo E-deficient mice (28). The percent of intimal area covered by lesions in RAG2 heterozygous and homozygous animals did not differ in any of the three aortic regions (Fig. $3 A$ ).

Extent of atherosclerosis was also evaluated by measurement of esterified and unesterified cholesterol in these three aortic regions. The relative accumulation of cholesterol correlated with the lesion area in all regions (Fig. 3, $B$ and $C$ ). There were no statistically significant differences between the heterozygous and homozygous RAG2 mice with regard to tissue cholesterol content in any of the three regions.

\section{Discussion}

The cellular and morphologic characteristics of atherosclerotic lesions that develop in apo E-/- mice are strikingly similar to those of human lesions (28). Therefore, apo E-deficient mice are being widely used to explore mechanisms of atherogenesis that may be relevant to human disease (30). RAG2-deficient mice have a deficiency of $\mathrm{B}$ and $\mathrm{T}$ lymphocytes that is complete and sustained (32). Therefore, the combination of apo E and RAG2 deficiencies in mice is well-suited to the investigation of the effect of total lymphocyte deficiency on atherogenesis.

The extent of atherosclerotic lesions induced in experimental studies varies widely, even in inbred mouse strains fed standardized diets and maintained in well-controlled environments. We therefore designed these studies with strict attention to both the mode of lesion quantification and statistical concerns. In mice, the extent of atherosclerosis is usually quantified only in the aortic root by morphometric techniques (44). A previous study has demonstrated an excellent correlation between extent of disease in the aortic root and that in the remainder of the aorta (45). Therefore, we elected to analyze the entire 

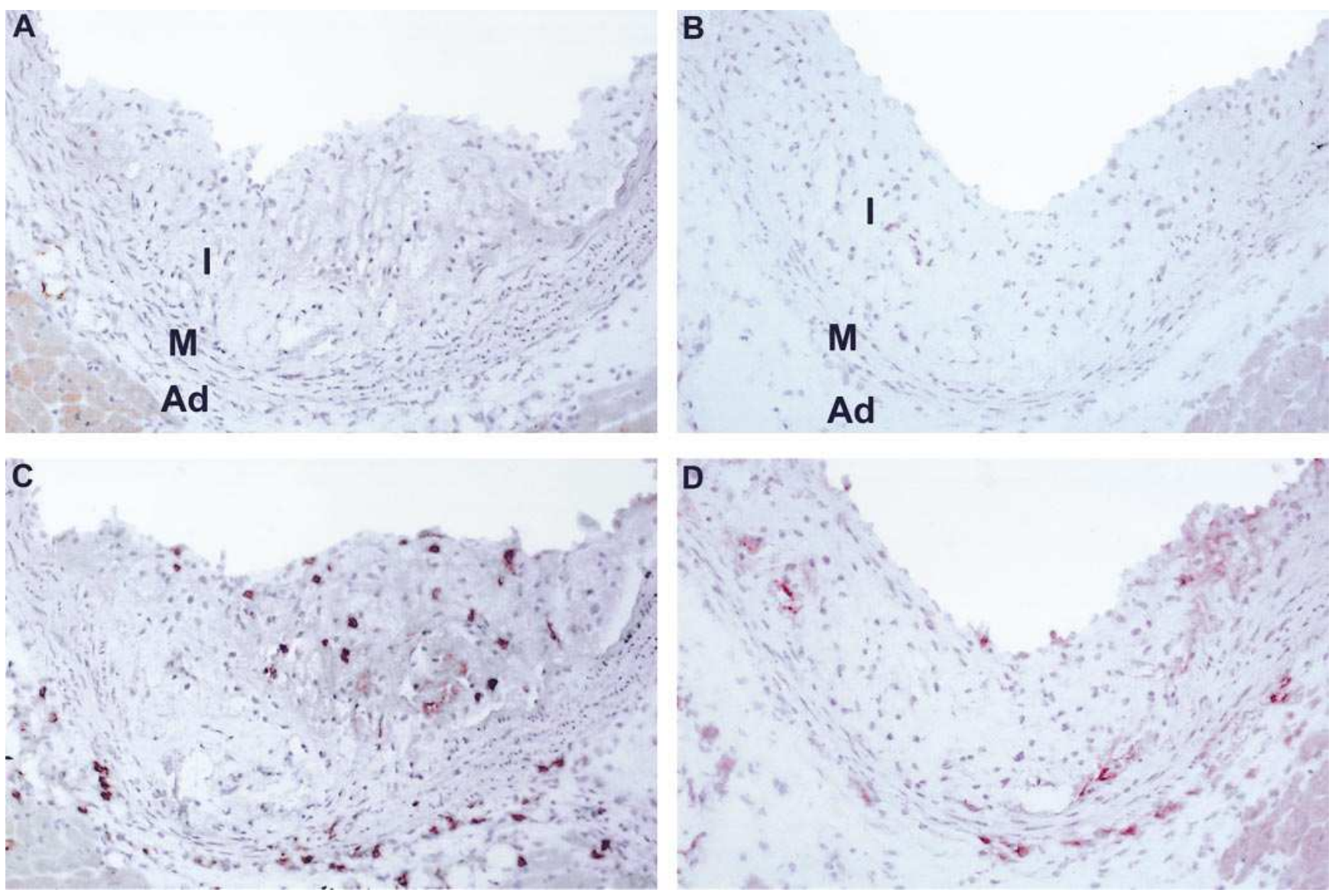

Figure 2. Reduced MHC class II-positive macrophages in lesions of apo E-/- $\times$ RAG $-/-$ mice. Serial sections of aortic root from a representative apo $\mathrm{E}-1-\times \mathrm{RAG} 2+/-$ mouse $(A$ and $C)$ and a representative apo $\mathrm{E}-1-\times \mathrm{RAG} 2-/-$ mouse $(B$ and $D)$. Sections were stained with secondary antibody alone $(A$ and $B)$ or with anti-MHC class II antibody ( $C$ and $D$ ). Regions of vasculature are denoted as $l$, lesions; $M$, media; and $A d$, adventitia. $\times 300$.

aorta for both intimal lesion area as well as tissue cholesterol content. These parameters of atherosclerosis for quantifying the extent of lesion formation have been used in numerous atherosclerosis experiments in larger species $(39,40,46)$, and have the major advantage of providing two independent parameters of disease extent over the entire aorta.

There has been considerable interest in the role of autoantibodies and immune complexes in the development of atherosclerosis $(15,16,17)$. The two antigens that have received the most attention are modified forms of lipoproteins and heat shock proteins. Serum titers of MDA-LDL autoantibodies correlate with the extent of carotid atherosclerosis as measured by ultrasound in humans (16) and with the extent of aortic atherosclerosis in LDL-receptor-/- mice (47). Despite these positive correlations, the specific role of autoantibodies is controversial, since immunization with MDA-LDL augmented autoantibody titers in Watanabe heritable hyperlipidemic rabbits but decreased the extent of atherosclerosis (48). In our study, the immunocompetent apo E-deficient mice had high titers of autoantibodies to MDA-LDL and the RAG2-/mice had no autoantibodies to MDA-LDL, yet there was no difference in the extent of atherosclerosis. Therefore, humoral immunity has no essential role in development of aortic atherosclerotic lesions in apo $\mathrm{E}-1-$ mice fed a modified diet.

The presence of activated $\mathrm{T}$ lymphocytes within atheroscle- rotic lesions is consistent with a role for these cells in atherogenesis. Cytokines secreted by activated $\mathrm{T}$ lymphocytes could change lipid and lipoprotein metabolism in macrophages. Cell culture studies have indicated that cytokines released from lymphocytes, such as IFN- $\gamma$ and IL-4, modulate several facets of macrophage lipid metabolism, including secretion of apo E (49), lipoprotein modification (50), and regulation of lipoprotein receptors such as scavenger receptors (51-53) and LDLrelated receptor protein (54).

T lymphocyte-derived IFN- $\gamma$ (55) and IL-4 (56) also increase the expression of MHC class II on macrophages. Macrophages expressing MHC class II were detected throughout the lesions of immunocompetent RAG2+/- mice. However, the presence of MHC class II-positive macrophages within lesions was markedly reduced in RAG2-/- mice, demonstrating that the infiltration of $\mathrm{T}$ lymphocytes into atherosclerotic lesions influences the phenotype of macrophages within lesions, but that this change does not affect the extent of atherosclerosis. The relationship between the MHC class II-positive macrophages and foam cells (which express low levels of MHC class II) is uncertain, but these results indicate that MHC class II-positive cells within lesion are not required for foam cell formation.

In conclusion, total lymphocyte deficiency induced by deletion of the RAG2 gene did not influence the extent of aortic 


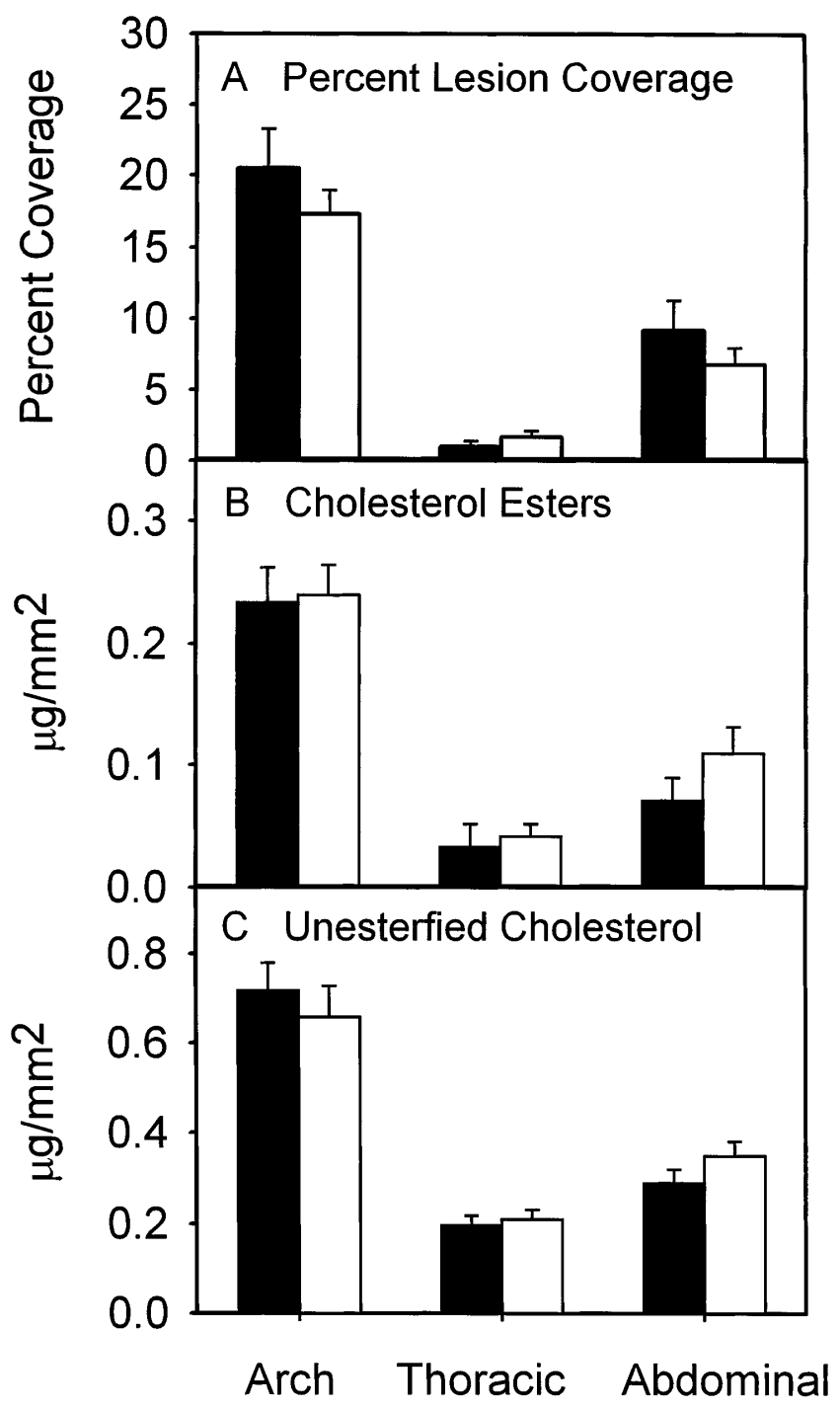

Figure 3. Quantification of the extent of aortic atherosclerosis in mouse aortas. Lesions were quantified by $(A)$ percent of aortic intima covered by grossly discernible lesions; $(B)$ content of cholesterol esters; and $(C)$ content of unesterified cholesterol. These parameters were measured in apo $\mathrm{E}-1-\times \mathrm{RAG} 2+/-($ closed bars, $n=25)$ and apo $\mathrm{E}-/-\times \mathrm{RAG} 2-/-($ open bars, $n=14)$ mice. Histobars represent the means and bars represent SEM.

atherosclerosis in apo $\mathrm{E}-/-$ mice fed a Western diet for 3 mo. Using different quantitative techniques, similar results have been reported recently in RAG1/apo E-deficient mice (57). Although total lymphocyte deficiency did not influence the extent of atherosclerosis at this time point, this result does not negate a role for this cell type in earlier or later stages of atherogenesis. Furthermore, these data do not abrogate a modulatory effect of specific subclasses of $\mathrm{T}$ lymphocytes on lesion development.

\section{Acknowledgments}

We thank Beth Engeszer, Sandra Sendobry, and Debra Rateri for editorial assistance, Kelly Hall for secretarial assistance, and Christine Healy for assistance with figure preparation.
Alan Daugherty is an Established Investigator of the American Heart Association. Simon Roselaar is a Research Fellow of the American Heart Association, Missouri Affiliate.

\section{References}

1. Shi, C.W., W.S. Lee, Q. He, D. Zhang, D.L. Fletcher, J.B. Newell, and E. Haber. 1996. Immunologic basis of transplant-associated arteriosclerosis. Proc. Natl. Acad. Sci. USA. 93:4051-4056.

2. Hansson, G.K., J. Holm, S. Holm, Z. Fotev, H.J. Hedrich, and J. Fingerle. 1991. Lymphocytes-T inhibit the vascular response to injury. Proc. Natl. Acad. Sci. USA. 88:10530-10534.

3. Hansson, G.K., and J. Holm. 1991. Interferon- $\gamma$ inhibits arterial stenosis after injury. Circulation. 84:1266-1272.

4. Libby, P., and G.K. Hansson. 1991. Involvement of the immune system in human atherogenesis - current knowledge and unanswered questions. Lab. Invest. 64:5-15.

5. Emeson, E.E., and A.L. Robertson, Jr. 1988. T lymphocytes in aortic and coronary intimas. Their potential role in atherogenesis. Am. J. Pathol. 130:369376.

6. Shimokama, T., S. Haraoka, and T. Watanabe. 1991. Immunohistochemical and ultrastructural demonstration of the lymphocyte-macrophage interaction in human aortic intima. Mod. Pathol. 4:101-107.

7. Jonasson, L., J. Holm, O. Skalli, G. Bondjers, and G.K. Hansson. 1986. Regional accumulations of T cells, macrophages, and smooth muscle cells in the human atherosclerotic plaque. Arteriosclerosis. 6:131-138.

8. Hansson, G.K., L. Jonasson, B. Lojsthed, S. Stemme, O. Kocher, and G. Gabbiani. 1988. Localization of T lymphocytes and macrophages in fibrous and complicated human atherosclerotic plaques. Atherosclerosis. 72:135-141.

9. Stemme, S., L. Rymo, and G.K. Hansson. 1991. Polyclonal origin of lymphocytes-T in human atherosclerotic plaques. Lab. Invest. 65:654-660.

10. Swanson, S.J., A. Rosenzweig, J.G. Seidman, and P. Libby. 1994. Diversity of T-cell antigen receptor $\mathrm{V}$ beta gene utilization in advanced human atheroma. Arterioscler. Thromb. 14:1210-1214.

11. Hansson, G.K., J. Holm, and L. Jonasson. 1989. Detection of activated T lymphocytes in the human atherosclerotic plaque. Am. J. Pathol. 135:169-175.

12. van der Wal, A.C., K.P. Dingemans, M. van den Bergh Weerman, P.K Das, and A.E. Becker. 1994. Specialized membrane contacts between immunocompentent cells in human atherosclerotic plaques. Cardiovasc. Pathol. 3:8185 .

13. Kishikawa, H., T. Shimokama, and T. Watanabe. 1993. Localization of T lymphocytes and macrophages expressing IL-1, IL-2 receptor, IL- 6 and TNF in human aortic intima. Role of cell-mediated immunity in human atherogenesis. Virchows Arch. A. Pathol. Anat. 423:433-442.

14. Rolfe, B.E., J.H. Campbell, N.J. Smith, M.W. Cheong, and G.R. Campbell. 1995. T lymphocytes affect smooth muscle cell phenotype and proliferation. Arterioscler. Thromb. Vasc. Biol. 15:1204-1210.

15. Xu, Q., J. Willeit, M. Marosi, R. Kleindienst, F. Oberhollenzer, S. Kiechl, T. Stulnig, G. Luef, and G. Wick. 1993. Association of serum antibodies to heat-shock protein 65 with carotid atherosclerosis. Lancet (N. Am. Ed.) 341: 255-259.

16. Salonen, J.T., S. Yla-Herttuala, R. Yamamoto, S. Butler, H. Korpela, R. Salonen, K. Nyyssonen, W. Palinski, and J.L. Witztum. 1992. Autoantibody against oxidised LDL and progression of carotid atherosclerosis. Lancet ( $N$. Am. Ed.) 339:883-887.

17. Kiener, P.A., B.M. Rankin, P.M. Davis, S.A. Yocum, G.A. Warr, and R.I. Grove. 1995. Immune complexes of LDL induce atherogenic responses in human monocytic cells. Arterioscler. Thromb. Vasc. Biol. 15:990-999.

18. Ylä-Herttuala, S., W. Palinski, S.W. Butler, S. Picard, D. Steinberg, and J.L. Witztum. 1994. Rabbit and human atherosclerotic lesions contain IgG that recognizes epitopes of oxidized LDL. Arterioscler. Thromb. 14:32-40.

19. Emeson, E.E., and M.L. Shen. 1993. Accelerated atherosclerosis in hyperlipidemic C57BL/6 mice treated with cyclosporin-A. Am. J. Pathol. 142: 1906-1915.

20. Roselaar, S.E., G. Schonfeld, and A. Daugherty. 1995. Enhanced development of atherosclerosis in cholesterol-fed rabbits by suppression of cellmediated immunity. J. Clin. Invest. 96:1389-1394.

21. Drew, A.F., and P.G. Tipping. 1995. Cyclosporine treatment reduces early atherosclerosis in the cholesterol-fed rabbit. Atherosclerosis. 116:181-189.

22. Emeson, E.E., M.L. Shen, C.G.H. Bell, and A. Qureshi. 1996. Inhibition of atherosclerosis in CD4 T-cell-ablated and nude (nu/nu) C57BL/6 hyperlipidemic mice. Am. J. Pathol. 149:675-685.

23. Fyfe, A.I., J.H. Qiao, and A.J. Lusis. 1994. Immune-deficient mice develop typical atherosclerotic fatty streaks when fed an atherogenic diet. J. Clin. Invest. 94:2516-2520.

24. Qiao, J.H., P.Z. Xie, M.C. Fishbein, J. Kreuzer, T.A. Drake, L.L. Demer, and A.J. Lusis. 1994. Pathology of atheromatous lesions in inbred and genetically engineered mice - genetic determination of arterial calcification. Arterioscler. Thromb. 14:1480-1497.

25. Roselaar, S.E., P.X. Kakkanathu, and A. Daugherty. 1996. Lymphocyte populations in atherosclerotic lesions of apoE -/- and LDL receptor -/- 
mice. Decreasing density with disease progression. Arterioscler. Thromb. Vasc. Biol. 16:1013-1018.

26. Zhou, X.H., S. Stemme, and G.K. Hansson. 1996. Evidence for a local immune response in atherosclerosis: CD4(+) T cells infiltrate lesions of apolipoprotein-E-deficient mice. Am. J. Pathol. 149:359-366.

27. Palinski, W., V.A. Ord, A.S. Plump, J.L. Breslow, D. Steinberg, and J.L. Witztum. 1994. ApoE-deficient mice are a model of lipoprotein oxidation in atherogenesis-demonstration of oxidation-specific epitopes in lesions and high titers of autoantibodies to malondialdehyde-lysine in serum. Arterioscler. Thromb. 14:605-616.

28. Nakashima, Y., A.S. Plump, E.W. Raines, J.L. Breslow, and R. Ross. 1994. ApoE-deficient mice develop lesions of all phases of atherosclerosis throughout the arterial tree. Arterioscler. Thromb. 14:133-140.

29. Reddick, R.L., S.H. Zhang, and N. Maeda. 1994. Atherosclerosis in mice lacking apoE-Evaluation of lesional development and progression. Arterioscler. Thromb. 14:141-147.

30. Breslow, J.L. 1996. Mouse models of atherosclerosis. Science (Wash. DC). 272:685-688.

31. Lichtman, A.H., M. Cybulsky, and F.W. Luscinskas. 1996. Immunology of atherosclerosis: the promise of mouse models. Am. J. Pathol. 149:351-357.

32. Shinkai, Y., G. Rathbun, K.-P. Lam, E.M. Oltz, V. Stewart, M. Mendelsohn, J. Charron, M. Datta, F. Young, A.M. Stall, and F.W. Alt. 1992. RAG2-deficient mice lack mature lymphocytes owing to inability to initiate V(D)J rearrangement. Cell. 68:855-867.

33. Piedrahita, J.A., S.H. Zhang, J.R. Hagaman, P.M. Oliver, and N. Maeda. 1992. Generation of mice carrying a mutant apolipoprotein-E gene inactivated by gene targeting in embryonic stem cells. Proc. Natl. Acad. Sci. USA. 89:4471-4475

34. Kung, J.T., S.O. Sharrow, D.G. Sieckmann, R. Lieberman, and W.E. Paul. 1981. A mouse IgM allotypic determinant (Igh-6.5) recognized by a monoclonal rat antibody. J. Immunol. 127:873-876.

35. Leo, O., D.H. Foo, L.E. Sachs, L.E. Samelson, and J.A. Bluestone. 1987. Identification of a monoclonal antibody specific for a murine T3 polypeptide. Proc. Natl. Acad. Sci. USA. 84:1374-1378.

36. Cole, T.G., R. Kitchens, A. Daugherty, and G. Schonfeld. 1990. An improved method for separation of triglyceride-rich lipoproteins by FPLC. Pharmacia Biocommunique. 4:4-6.

37. Haberland, M.E., A.M. Fogelman, and P.A. Edwards. 1982. Specificity of receptor-mediated recognition of malondialdehyde-modified low density lipoproteins. Proc. Natl. Acad. Sci. USA. 79:1712-1716.

38. Ishikawa, T.T., J. MacGee, J.A. Morrison, and C.J. Glueck. 1974. Quantitative analysis of cholesterol in 5 and $20 \mu$ l of plasma. J. Lipid Res. 15:286-291.

39. Daugherty, A., B.S. Zweifel, and G. Schonfeld. 1991. The effects of probucol on the progression of atherosclerosis in mature Watanabe heritable hyperlipidaemic rabbits. Br. J. Pharmacol. 103:1013-1018.

40. Daugherty, A., and S.E. Roselaar. 1995. Lipoprotein oxidation as a mediator of atherogenesis: insights from pharmacological studies. Cardiovasc. Res. 29:297-311.

41. Bligh, E.G., and W.J. Dyer. 1959. A rapid method of total lipid extraction and characterization. Can. J. Physiol. Pharmacol. 37:911-916.

42. Plump, A.S., J.D. Smith, T. Hayek, K. Aaltosetala, A. Walsh, J.G. Verstuyft, E.M. Rubin, and J.L. Breslow. 1992. Severe hypercholesterolemia and atherosclerosis in apolipoprotein-E-deficient mice created by homologous recombination in ES cells. Cell. 71:343-353.

43. Zhang, S.H., R.L. Reddick, J.A. Piedrahita, and N. Maeda. 1992. Spontaneous hypercholesterolemia and arterial lesions in mice lacking apolipoprotein E. Science (Wash. DC). 258:468-471.

44. Paigen, B., A. Morrow, P. Holmes, D. Mitchell, and R. Williams. 1987. Quantitative assessment of atherosclerotic lesions in mice. Atherosclerosis. 68 : 231-240.

45. Tangirala, R.K., E.M. Rubin, and W. Palinski. 1995. Quantitation of atherosclerosis in murine models: correlation between lesions in the aortic origin and in the entire aorta, and differences in the extent of lesions between sexes in LDL receptor-deficient and apolipoprotein E-deficient mice. J. Lipid Res. 36:2320-2328.

46. Daugherty, A., B.S. Zweifel, and G. Schonfeld. 1989. Probucol attenuates the development of aortic atherosclerosis in cholesterol-fed rabbits. $B r . J$. Pharmacol. 98:612-618.

47. Palinski, W., R.K. Tangirala, E. Miller, S.G. Young, and J.L. Witztum. 1995. Increased autoantibody titers against epitopes of oxidized LDL in LDL receptor-deficient mice with increased atherosclerosis. Arterioscler. Thromb. Vasc. Biol. 15:1569-1576.

48. Palinski, W. E. Miller, and J.L. Witztum. 1995. Immunization of low density lipoprotein (LDL) receptor-deficient rabbits with homologous malondialdehyde-modified LDL reduces atherogenesis. Proc. Natl. Acad. Sci. USA 92:821-825.

49. Brand, K., N. Mackman, and L.K. Curtiss. 1993. Interferon- $\gamma$ inhibits macrophage apolipoprotein-E production by posttranslational mechanisms. $J$. Clin. Invest. 91:2031-2039.

50. Fong, L.G., T.S.E. Albert, and S.E. Hom. 1994. Inhibition of the macrophage-induced oxidation of low density lipoprotein by interferon- $\gamma$. J. Lipid Res. 35:893-904

51. Fong, L.G., T.A.T. Fong, and A.D. Cooper. 1990. Inhibition of mouse macrophage degradation of acetyl low density lipoprotein by interferon- $\gamma$. $J$. Biol. Chem. 265:11751-11760.

52. Geng, Y.J., and G.K. Hansson. 1992. Interferon- $\gamma$ inhibits scavenger receptor expression and foam cell formation in human monocyte-derived macrophages. J. Clin. Invest. 89:1322-1330.

53. de Villiers, W.J.S., I.P. Fraser, and S. Gordon. 1994. Cytokine and growth factor regulation of macrophage scavenger receptor expression and function. Immunol. Lett. 43:73-79.

54. LaMarre, J., B.B. Wolf, E.L.W. Kittler, P.J. Quesenberry, and S.L. Gonias. 1993. Regulation of macrophage $\alpha 2$-macroglobulin receptor/low density lipoprotein receptor-related protein by lipopolysaccharide and interferon- $\gamma . J$. Clin. Invest. 91:1219-1224.

55. Steeg, P.S., R.N. Moore, H.M. Johnson, and J.J. Oppenheim. 1982. Regulation of murine macrophage Ia antigen expression by a lymphokine with im mune interferon activity. J. Exp. Med. 156:1780-1793.

56. Stuart, P.M., A. Zlotnik, and J.G. Woodward. 1988. Induction of class I and class II MHC antigen expression on murine bone marrow-derived macrophages by IL-4 (B cell stimulatory factor 1). J. Immunol. 140:1542-1547.

57. Dansky, H.M., S.A. Charlton, M.M. Harper, and J.D Smith. 1997. T and B lymphocytes play a minor role in atherosclerotic plaque formation in the apolipoprotein E-deficient mouse. Proc. Natl. Acad. Sci. USA. 94:4642-4646. 